\title{
Cinética digestiva e eficiência de síntese de proteína microbiana em novilhos alimentados com farelo de girassol e diferentes fontes energéticas ${ }^{1}$
}

\section{Ana Rosália Mendes ${ }^{2}$, Jane Maria Bertocco Ezequiel ${ }^{3}$, Rosemary Laís Galati ${ }^{2}$, Virgílio Franco do Nascimento ${ }^{4}$, Mário Adriano Ávila Queiroz ${ }^{5}$, Expedita Maria de Oliveira Pereira ${ }^{6}$}

\author{
${ }^{1}$ Parte da tese de Doutorado da primeira autora. Projeto financiado pela FAPESP. \\ ${ }^{2}$ Doutora em Zootecnia pela FCAVIUNESP, Jaboticabal - SP. \\ ${ }^{3}$ FCAVIUNESP, Via de acesso Prof. Dr. Paulo Donato Castellane, s/n, CEP: 14884-900, Jaboticabal, SP. \\ ${ }^{4}$ CENA/USP, Piracicaba - SP. \\ ${ }^{5}$ Doutorando em Ciência Animal pela ESALQ/USP, Piracicaba - SP. \\ ${ }^{6}$ Mestre em Zootecnia pela FCAVIUNESP, Jaboticabal - SP.
}

RESUMO - Objetivou-se avaliar o efeito da substituição parcial do milho pela casca de soja e pelo farelo de gérmen de milho sobre a produção e eficiência de síntese de proteína microbiana e sobre as taxas de diluição e passagem ruminal. Foram utilizados três novilhos de corte, mestiços, canulados no rúmen e no duodeno, distribuídos em dois delineamentos em quadrado latino $3 \times 3$. As dietas experimentais, à base de silagem de milho (60\%), apresentavam como fonte de proteína farelo de girassol e, como fonte de energia, milho (MI) ou sua substituição parcial pela casca de soja (CS) ou pelo farelo de gérmen de milho (FGM). Para o isolamento da massa microbiana, foram coletadas amostras de conteúdo ruminal às 3, 6, 9 e 12 horas após a alimentação. Utilizaram-se RNA como marcador microbiano e dicromato de sódio e Co-EDTA como indicadores das taxas de passagem e de diluição, respectivamente. A composição dos microrganismos ruminais não foi influenciada pelas dietas experimentais ou pelos horários de coleta. Não houve diferenças significativas no fluxo de matéria orgânica, carboidratos totais, nitrogênio e nitrogênio microbiano para o duodeno e na eficiência de síntese de proteína microbiana. As taxas de diluição foram semelhantes entre as dietas, com média de 13,4\%/h. A taxa de passagem da silagem de milho mordentada foi menor, com tendência de menor taxa de passagem também para o farelo de girassol na dieta MI. A casca de soja e o farelo de gérmen de milho podem substituir parcialmente o milho, proporcionando ambiente ruminal adequado ao desenvolvimento da flora microbiana e conseqüente produção de proteína microbiana ruminal em novilhos confinados.

Palavras-chave: casca de soja, farelo de gérmen de milho, microrganismos ruminais, taxa de diluição, taxa de passagem

\section{Digestion kinetics and efficiency of microbial protein synthesis on beef steers fed sunflower meal and different energy sources}

\begin{abstract}
The objective of this trial was to evaluate the partial replacement of ground corn with soybean hulls or corn germ meal on ruminal microbial protein synthesis and efficiency and ruminal dilution and passage rates. Three crossbreed steers fitted with ruminal and duodenal cannulas were assigned to two 3 x 3 Latin squares. The experimental diets contained: corn silage (60\%), sunflower meal and ground corn (GC diet) that was partially replaced with soybean hulls (SBH diet) or corn germ meal (CGM diet). Ruminal fluid was collected at 3, 6, 9, and 12 hours after feeding for isolation of ruminal microbes. RNA was used as the microbial marker while sodium dicromate and Co-EDTA were used as passage and dilution rate markers, respectively. Ruminal microbial composition was not affected by diets and time after feeding in the present trial. Moreover, duodenal flows of organic matter, total carbohydrates, nitrogen $(\mathrm{N})$, and microbial $\mathrm{N}$ as well as microbial efficiency were all not significantly changed across diets. Fluid dilution rate also did not differ and averaged $13.4 \% / \mathrm{h}$ among diets. Ruminal passage rate of mordant corn silage was lower and a trend for lower passage rate of sunflower meal on GC diet also was observed. Soybean hulls and corn germ meal can partially replace ground corn on diets for confined steers because they provided adequate ruminal environment for microbial growth and microbial protein synthesis.
\end{abstract}

Key Words: corn germ meal, dilution rate, ruminal microbial, passage rate, soybean hulls

\section{Introdução}

A fermentação ruminal e a passagem de proteína microbiana ou da dieta para o intestino delgado são afetadas pela ingestão quantitativa das fontes de energia e de proteína da dieta (Clark et al., 1992). Alimentos pouco degradados no rúmen aumentam a quantidade de proteína que chega ao duodeno, mas diminuem a concentração de proteína microbiana sintetizada no rúmen. Segundo o NRC (1996), a proteína microbiana pode suprir de 50 a 100\% da

Correspondências devem ser enviadas para: mendesar@yahoo.com.br 
proteína metabolizável requerida para bovinos de corte, dependendo do conteúdo de proteína não-degradável na dieta. Dessa forma, a eficiência de síntese de proteína microbiana é economicamente importante para os requerimentos de proteína metabolizável.

A dieta é fundamental para otimizar a produção microbiana e sua eficiência fermentativa no ambiente ruminal. O excesso de carboidratos não-estruturais pode diminuir o pH ruminal e a eficiência de síntese microbiana, ao passo que a falta de carboidratos com taxas de fermentação mais rápidas reduz o nível de energia disponível para o crescimento bacteriano (Clark, 1992). Portanto, a fonte de carboidratos não-estruturais nas dietas pode maximizar a síntese de proteína microbiana no rúmen.

Eramus et al. (1994), ao estudarem o efeito da fonte de proteína sobre a síntese de $\mathrm{N}$ microbiano, observaram que a dieta com farelo de girassol proporcionou maior fluxo de $\mathrm{N}$ microbiano para o duodeno que aquelas com farelo de glúten de milho e farinha de sangue. Esses autores constataram tendência de maior eficiência de síntese microbiana para as dietas com farelo de girassol (43,0 vs 36,5 e 36,6 g de $\mathrm{N}$ microbiano/kg de matéria orgânica aparentemente digerida no rúmen, para dietas com farinha de sangue e farelo de glúten de milho, respectivamente) e creditaram esse efeito à alta taxa de fermentação ruminal do farelo de girassol.

De acordo com Clark et al. (1992), a sincronização da liberação de energia e nitrogênio dos alimentos pela degradação ruminal é necessária para potencializar a fermentação e síntese de proteína microbiana ruminal. Portanto, fontes alternativas de energia devem ser avaliadas juntamente com o farelo de girassol, para maximização da síntese e eficiência microbiana.

O farelo de gérmen de milho apresentou degradabilidade efetiva de $8 \% / h$, superior à do milho e da casca de soja (Galati et al., 2002a), sugerindo que a combinação desse ingrediente com o farelo de girassol pode ser interessante, para maximização da fermentação ruminal e, conseqüentemente, da produção microbiana. Grigsby et al. (1993) observaram que a substituição do milho pela casca de soja, na suplementação de novilhos alimentados com feno de baixa qualidade promoveu efeito quadrático sobre o fluxo de $\mathrm{N}$ microbiano para o duodeno, apresentando fluxo máximo de N quando a relação casca de soja e milho foi de 66:34.

A composição dos microrganismos do rúmen varia conforme a fase do crescimento microbiano, a disponibilidade de nutrientes e o tipo de microrganismo (Owens \& Goetsch, 1988). Cecava et al. (1990) afirmaram que essa variação também ocorre de acordo com o horário em que a amostragem é feita. Segundo Clark et al. (1992), as variações na composição das bactérias ruminais podem ser atribuídas às diferenças entre técnicas de isolamento e de determinação da composição das bactérias. Entretanto, utilizando-se as mesmas técnicas, podem ocorrer diferenças significativas na composição das bactérias isoladas em animais alimentados com diferentes dietas.

A disponibilidade de energia e nitrogênio para os microrganismos é determinada pelas taxas de digestão e passagem pelo rúmen, que influenciam a eficiência e a quantidade de proteína microbiana sintetizada. A taxa de passagem consiste no fluxo de resíduos não-digeridos pelo trato digestivo. O fluxo ruminal inclui, além da fibra indigestível, bactérias e outras frações não-degradáveis do alimento. A origem e o processamento do alimento são variáveis que influenciam a digestão, a taxa de digestão e a reciclagem do conteúdo ruminal (Van Soest, 1994).

Kovács et al. (1998) diferenciaram a taxa de passagem do fluido ruminal e da passagem da fibra e concluíram que o aumento da taxa de passagem de fluido, ou taxa de diluição, pode influenciar a digestão e aumentar a taxa de passagem, em razão da mudança da consistência física da digesta ruminal. Avaliando a substituição do milho pela casca de soja, Mansfield \& Stern (1994) observaram taxa de diluição semelhante entre as dietas (média de 13,5\%/h), mas notaram maior volume ruminal para as dietas com a casca de soja, sugerindo que essa expansão tenha sido promovida por um mecanismo compensatório provocado pela digestão ruminal da casca de soja.

O objetivo neste trabalho foi avaliar o efeito da substituição parcial do milho pela casca de soja e pelo farelo de gérmen de milho, associados ao farelo de girassol como fonte protéica, em dietas para novilhos, sobre a produção e eficiência de síntese de proteína microbiana e as taxas de diluição e de passagem ruminal.

\section{Material e Métodos}

Três novilhos de corte mestiços de aproximadamente 20 meses e com $370 \mathrm{~kg}$ de peso médio inicial, castrados, providos de cânulas no rúmen e do tipo T no duodeno, foram alojados em baias individuais, com piso de cimento e água à vontade. A cada três meses, os animais receberam vermífugo na dose recomendada.

A composição química dos ingredientes utilizados na formulação das dietas foi descrita por Mendes et al. (2005). As dietas experimentais, fornecidas duas vezes ao dia, foram constituídas de $60 \%$ de silagem de milho e $40 \%$ de concentrado, tendo o farelo de girassol como fonte de proteína, o milho (MI) como fonte de energia ou sua subs- 
tituição parcial $(58,6 \%)$ por casca de soja (CS) ou farelo de gérmen de milho (FGM), de acordo com a composição das dietas experimentais (Tabela 1). As dietas, isoprotéicas, foram formuladas para atender às exigências para ganho de $1,2 \mathrm{~kg} /$ dia, segundo NRC (1996).

Os alimentos foram fornecidos em quantidade ajustada para que houvesse sobras de 5 a $10 \%$, efetuando-se diarimente o controle, por meio da pesagem e amostragem dos alimentos e das sobras. As amostras de silagem de milho e de sobras foram pré-secas a $55^{\circ} \mathrm{C}$ por 72 horas. Todas as amostras foram moídas a $1 \mathrm{~mm}$, para determinação dos teores de MS, MO e PB, pelo método de Kjeldahl;

Tabela 1 - Composições percentual e química das dietas experimentais

Table 1 - Ingredient and chemical compositions of the experimental diets

\begin{tabular}{lccc}
\hline $\begin{array}{l}\text { Ingrediente (\%) } \\
\text { Ingredient (\%) }\end{array}$ & \multicolumn{3}{c}{$\begin{array}{c}\text { Dieta } \\
\text { Diet }\end{array}$} \\
\cline { 2 - 4 } & \begin{tabular}{c} 
MI \\
\multicolumn{1}{l}{ GC }
\end{tabular} & $\begin{array}{c}\text { SBH } \\
\text { CGM }\end{array}$ \\
\hline $\begin{array}{l}\text { Silagem de milho } \\
\text { Corn silage }\end{array}$ & 60,0 & 60,0 & 60,0 \\
$\begin{array}{l}\text { Milho } \\
\text { Corn }\end{array}$ & 18,9 & 8,2 & 8,2 \\
$\begin{array}{l}\text { Casca de soja } \\
\text { Soybean hulls }\end{array}$ & - & 11,6 & - \\
$\begin{array}{l}\text { Farelo de gérmen de milho } \\
\text { Corn germ meal }\end{array}$ & - & - & 11,6 \\
$\begin{array}{l}\text { Farelo de girassol } \\
\text { Sunflower meal } \\
\begin{array}{l}\text { Suplemento mineral } \\
\text { Mineral supplement }\end{array}\end{array}$ & 20,4 & 19,7 & 19,7 \\
\hline
\end{tabular}

Composição química (\% MS)

Chemical composition (\% DM)

\begin{tabular}{|c|c|c|c|}
\hline Matéria orgânica & 95,9 & 95,8 & 95,8 \\
\hline \multicolumn{4}{|l|}{ Organic matter } \\
\hline Proteína bruta & 13,0 & 13,1 & 13,2 \\
\hline \multicolumn{4}{|l|}{ Crude protein } \\
\hline FDN & 49,8 & 55,5 & 51,5 \\
\hline \multicolumn{4}{|l|}{$N D F$} \\
\hline FDA & 28,3 & 33,5 & 28,2 \\
\hline \multicolumn{4}{|l|}{$A D F$} \\
\hline Celulose & 21,9 & 26,6 & 22,0 \\
\hline \multicolumn{4}{|l|}{ Cellulose } \\
\hline Lignina & 6,4 & 6,9 & 6,2 \\
\hline \multicolumn{4}{|l|}{ Lignin } \\
\hline Extrato etéreo & 2,2 & 1,9 & 1,9 \\
\hline \multicolumn{4}{|l|}{ Ether extract } \\
\hline Amido & 26,6 & 20,9 & 24,9 \\
\hline \multicolumn{4}{|l|}{ Starch } \\
\hline $\mathrm{CNE}^{1}$ & 31,8 & 26,2 & 30,2 \\
\hline$N S C^{1}$ & & & \\
\hline
\end{tabular}

${ }^{1}$ Carboidratos não-estruturais $(C N E)=$ MO - PB - EE - FDN (corrigido para proteína), Sniffen et al. (1992).

${ }^{1}$ Nonstructural carbohydrates (NSC) $=O M-C P-E E-N D F$ (corrected for protein), Sniffen et al. (1992).

$\mathrm{MI}=$ dieta formulada com milho; CS = substituição parcial do milho pela casca de soja; FGM = substituição parcial do milho pelo farelo de gérmen de milho.

$G C=$ diet formulated with corn; $S B H=$ corn partially replaced with soybean hulls; $C G M=$ corn partially replaced with corn germ meal. extrato etéreo (EE), segundo metodologia descrita pela AOAC (1995); FDN, FDA, celulose e lignina, conforme o método descrito por Silva \& Queiroz (2002). A porcentagem de amido foi determinada utilizando-se a metodologia descrita por Hendrix (1993), para a extração, e o ácido dinitrosalicínico (DNSA), para a leitura colorimétrica (Miller, 1959).

Cada período experimental consistiu de 14 dias para adaptação e 10 para coleta de amostras para isolamento de massa microbiana ruminal e cálculo das taxas de diluição e passagem dos ingredientes.

O isolamento da massa microbiana ruminal foi realizado conforme Cecava et al. (1990), efetuando-se quatro coletas de 1,5 L de conteúdo ruminal, ao qual foram adicionados $500 \mathrm{~mL}$ de $\mathrm{NaCl} 1 \mathrm{~mol} / \mathrm{L}$. O líquido foi homogeneizado e filtrado em tecido de náilon $(100 \mu \mathrm{m})$ 3, 6, 9 e 12 horas após a alimentação. Seqüencialmente, as amostras de massa microbiana foram liofilizadas e pesadas. Os teores de MS, $\mathrm{MO}$ e $\mathrm{N}$ das amostras de massa microbiana ruminal foram obtidos segundo técnicas descritas pela AOAC (1995), por animal e por horário de coleta. Para estimativa da eficiência de síntese de proteína microbiana, utilizou-se uma amostra composta por horários por animal, para determinação da relação entre o nitrogênio do ácido ribonucléico pelo nitrogênio total (N-RNA:N total), quantificada conforme proposto por Zinn \& Owens (1986).

O fluxo duodenal foi estimado por meio da FDN indigestível, conforme metodologia descrita por Mendes et al. (2005). Os níveis de matéria orgânica, carboidrato e energia aparentemente digeridos no rúmen foram obtidos pela ingestão diária subtraída do fluxo duodenal.

Foi determinada a cinética digestiva no rúmen utilizando-se cromo mordentado como indicador de fase sólida de cada ingrediente e Co-EDTA como indicador de fase líquida (Úden et al., 1980). Imediatamente antes da alimentação, adicionaram-se $50 \mathrm{~g}$ de Co-EDTA diluídos em $500 \mathrm{~mL}$ de água no rúmen de cada animal. As amostragens de líquido ruminal foram realizadas antes e a cada duas horas após a adição da mistura até completar 12 horas. O conteúdo ruminal foi filtrado em tecido de náilon ( $50 \mu \mathrm{m})$ para obtenção do fluido e a parte sólida foi recolocada no rúmen. As amostras de líquido ruminal foram identificadas e congeladas para posteriores análises. Determinou-se a concentração de cobalto no indicador (Co-EDTA), pela digestão nítrico-perclórica e posterior leitura em espectrofotômetro de absorção atômica. Todas as amostras foram descongeladas e centrifugadas duas vezes a $500 \mathrm{x}$ g por 15 minutos e o sobrenadante foi submetido à leitura em espectrofotômetro de absorção atômica. O volume de líquido 
ruminal, a taxa de diluição, o tempo de reciclagem e o fluxo de líquido ruminal foram estimados utilizando-se os parâmetros da equação de regressão linear do logaritmo natural das concentrações de cobalto (mg/100 mL) nas amostras de líquido ruminal retiradas nos diferentes tempos. O volume ruminal foi estimado dividindo-se o total do indicador $(\mathrm{mg})$ adicionado no rúmen pelo antilogaritmo dos interceptos dessas equações. A taxa de diluição foi representada pelos coeficientes de regressão obtidos por meio das equações para cada tratamento e do período de avaliação. A partir desses parâmetros (taxa de diluição e volume ruminal), estimaram-se o tempo de reciclagem (100/taxa de diluição) e o fluxo ruminal (volume ruminal x taxa de diluição/100).

Os ingredientes das dietas (silagem de milho, farelo de girassol, milho, casca de soja e farelo de gérmen de milho) foram mordentados com dicromato de sódio (Úden et al., 1980), para estimativa da taxa de passagem da fase sólida. A cada período experimental os animais recebiam $100 \mathrm{~g}$ de milho, casca de soja ou farelo de gérmen de milho mordentado, conforme a dieta com que se alimentavam, $100 \mathrm{~g}$ de farelo de girassol e $100 \mathrm{~g}$ de silagem de milho mordentados, em intervalos de 24 horas entre cada ingrediente, após o fim da coleta das amostras. O ingrediente mordentado foi adicionado imediatamente antes da primeira alimentação do dia e as amostras de digesta ruminal foram coletadas $0,3,6,9,12$ e 24 horas após a introdução do ingrediente mordentado no rúmen. A silagem de milho mordentada foi administrada 0,3 , 6, 9, 12, 24 e 48 horas após sua introdução.

As amostras de digesta ruminal foram pré-secas a $55^{\circ} \mathrm{C}$ por 72 horas e moídas a 1 mm para determinação da concentração de cromo. Parcelas de $1 \mathrm{~g}$ das amostras de digesta ruminal e de cada ingrediente mordentado foram colocadas em receptáculo especial (polyethylene $X$-ray sample cups, Chemplex Industries, USA) para determinação dos teores de cromo por meio de EDXRF (fluorescência de raios X por dispersão de energia), feita individualmente, de modo que cada ingrediente correspondeu, em cada animal, ao horário de coleta e ao período experimental. As amostras foram excitadas por 50 segundos em tubo de raios $\mathrm{X}$ com alvo de molibdênio e filtro de zircônio (Nascimento Filho et al., 1997), operado a $10 \mathrm{kV} / 20 \mathrm{~mA}$. Os espectros obtidos foram interpretados pelo aplicativo AXIL - Analysis of X-Ray Spectra by Interative Least Squares (Van Espen et al., s/d) e, a partir das intensidades dos raios $\mathrm{X}$ característicos, calcularam-se as concentrações (Nascimento Filho et al., 1997). A velocidade de trânsito da digesta ruminal foi determinada pela metodologia proposta por Orskov \& McDonald (1979).
Os animais foram distribuídos em dois delineamentos em quadrado latino 3 x 3 e os dados submetidos à análise de variância, comparando-se as diferenças entre médias pelo teste Tukey (5\%), pelo procedimento GLM do Statistical Analysis Systems ${ }^{\circledR}$ (SAS, 1995).

\section{Resultados e Discussão}

Os valores de composição das massas microbianas isoladas do líquido ruminal, de acordo com as dietas avaliadas, encontram-se na Tabela 2 e, de acordo com o horário de coleta, na Tabela 3. Não houve diferença significativa entre as dietas na composição das massas microbianas isoladas do líquido ruminal. Entretanto, a dieta MI apresentou valores de produção microbiana (g de massa microbiana/L de líquido ruminal) 13,9\% inferiores à média das demais.

Os valores percentuais de matéria orgânica (MO) da massa microbiana foram muito baixos em relação aos encontrados na literatura (Tabela 2), possivelmente em razão da adição de $50 \mathrm{~mL}$ de solução salina $1 \mathrm{~mol} / \mathrm{L}$ durante a última centrifugação no processo de isolamento da massa microbiana, acarretando maior valor de matéria mineral nas amostras. Essa hipótese também foi apontada por Valadares Filho (1995) como causa da grande variação nos valores de MO microbiana encontrados na literatura.

Em decorrência dos elevados valores de matéria mineral, a porcentagem de nitrogênio pode ter sido subestimada, mas, em comparação à MO (8,7\%), está de acordo com os dados encontrados na literatura (9,10; 8,50 e 9,96\%, Silveira, 2001; Valadares Filho, 1995; e Clark et al., 1992, respectivamente). Os valores médios obtidos para RNA $(4,05 \%)$ e relação N:RNA $(0,61)$ estão dentro das amplitudes citadas por Clark et al. (1992), de 2,40\% a 13,02\% para RNA e de 0,61 a 2,13 para a relação N:RNA.

As relações N-RNA:N total observadas nos isolados de microrganismos entre as diferentes dietas não apresentaram efeito significativo e a média de 0,12 encontra-se nos limites de 0,12 a 0,24 descritos por Valadares Filho (1995). Ítavo et al. (2002) avaliaram diferentes níveis de concentrado (20, 40, 60 e 80\%), em novilhos, e encontraram média de 0,15 para a relação N-RNA:N-total.

A composição da massa microbiana ruminal não foi afetada pelo horário de coleta do líquido ruminal. Esses resultados contradizem os observados por Cecava et al. (1990), que verificaram efeitos linear decrescente, para a porcentagem de MO, e quadrático, para os teores de nitrogênio, com maiores valores 9 horas após a alimentação. No entanto, registraram menor produção (g de massa 
Tabela 2 - Produção e composição da massa microbiana ruminal de novilhos de acordo com as dietas experimentais Table 2 - Production and composition of ruminal microbial isolated from steers fed the experimental diets

\begin{tabular}{|c|c|c|c|c|}
\hline \multirow[t]{3}{*}{$\begin{array}{l}\text { Ingrediente (\%) } \\
\text { Ingredient (\%) }\end{array}$} & \multicolumn{3}{|c|}{$\begin{array}{l}\text { Dieta } \\
\text { Diet }\end{array}$} & \multirow[t]{3}{*}{ CV $(\%)$} \\
\hline & MI & CS & FGM & \\
\hline & $G C$ & $S B H$ & $C G M$ & \\
\hline $\begin{array}{l}g \text { de microrganismos/L de líquido ruminal } \\
g \text { of microrganisms } / L \text { of ruminal fluid }\end{array}$ & 5,02 & 5,82 & 5,84 & 24,80 \\
\hline Matéria orgânica (\%) & 56,37 & 56,23 & 58,40 & 7,32 \\
\hline Organic matter (\%) & & & & \\
\hline $\begin{array}{l}\text { Nitrogênio (\% MS) } \\
\text { Nitrogen }(\% \text { DM) }\end{array}$ & 4,87 & 4,93 & 5,06 & 4,40 \\
\hline $\begin{array}{l}\text { Nitrogênio (\% MO) } \\
\text { Nitrogen (\% OM) }\end{array}$ & 8,65 & 8,79 & 8,67 & 5,64 \\
\hline $\begin{array}{l}\text { RNA (\% MS) } \\
\text { RNA (\% DM) }\end{array}$ & 4,62 & 3,80 & 3,74 & 23,09 \\
\hline $\begin{array}{l}\mathrm{N}: \mathrm{RNA} \\
N: R N A\end{array}$ & 0,69 & 0,57 & 0,56 & 23,09 \\
\hline $\begin{array}{l}\text { N-RNA:N total } \\
N \text {-RNA: total } N\end{array}$ & 0,14 & 0,12 & 0,11 & 22,19 \\
\hline
\end{tabular}

Médias nas linhas não diferem entre si pelo teste Tukey $(P<0,05)$. MI = dieta formulada com milho; $C S$ = substituição parcial do milho pela casca de soja; FGM = substituição parcial do milho pelo farelo de gérmen de milho. $\mathrm{CV}=$ coeficiente de variação. RNA = ácido ribonucléico N:RNA = relação nitrogênio:ácido nucléico; N-RNA:N total = relação nitrogênio do ácido ribonucléico:nitrogênio total.

Means within a row do not differ $(P<0.05)$ by Tukey test. $G C=$ diet formulated with corn; $S B H=$ corn partially replaced with soybean hulls; $C G M=$ corn partially replaced with corn germ meal. $C V=$ coefficient of variation. $R N A=$ ribonucleic acid; $N: R N A=$ nitrogen and ribonucleic acid ratio; $N$ - $R N A$ :total $N=$ ribonucleic acid nitrogen and total nitrogen ratio.

Tabela 3 - Efeito do tempo após alimentação sobre a produção e composição da massa microbiana isolada do líquido ruminal de novilhos

Table 3 - Effect of time after feeding on production and composition of microbial isolated from ruminal fluid of steers

\begin{tabular}{|c|c|c|c|c|c|}
\hline & \multicolumn{4}{|c|}{$\begin{array}{l}\text { Horas após alimentação } \\
\text { Hours after feeding }\end{array}$} & \multirow[t]{2}{*}{ CV (\%) } \\
\hline & 3 & 6 & 9 & 12 & \\
\hline $\begin{array}{l}\text { g de massa microbiana/L de líq. ruminal } \\
g \text { of microbial mass/L of ruminal fluid }\end{array}$ & $4,77 b$ & $5,91 \mathrm{ab}$ & $6,13 a$ & $5,42 \mathrm{ab}$ & 24,81 \\
\hline $\begin{array}{l}\text { Matéria orgânica (\%) } \\
\text { Organic matter (\%) }\end{array}$ & 57,55 & 56,61 & 57,45 & 56,44 & 7,32 \\
\hline $\begin{array}{l}\text { Nitrogênio (\% MS) } \\
\text { Nitrogen (\% DM) }\end{array}$ & 5,00 & 4,94 & 4,94 & 4,94 & 7,84 \\
\hline $\begin{array}{l}\text { Nitrogênio (\% MO) } \\
\text { Nitrogen }(\% O M)\end{array}$ & 8,70 & 8,74 & 8,62 & 8,77 & 5,66 \\
\hline
\end{tabular}

Médias, na linha, seguidas de letras diferentes diferem $(P<0,05)$ pelo teste Tukey.

Means followed by different letters in the row differ $(P<0.05)$ by Tukey test.

$\mathrm{MI}=$ dieta formulada com milho; CS = substituição parcial do milho pela casca de soja; FGM = substituição parcial do milho pelo farelo de gérmen de milho. $\mathrm{CV}=$ coeficiente de variação.

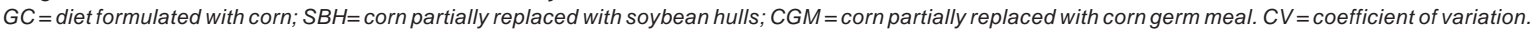

microbiana ruminal/L de líquido ruminal) 3 horas após a alimentação, indicando ser necessário período de até 3 horas após a ingestão de alimentos para a mastigação, hidratação e colonização do material ingerido. Ezequiel et al. (2002) avaliaram a produção de bactérias no líquido ruminal (BLA) de bovinos 1h, 2h30 e 11h30 após a alimentação e constataram valores numericamente maiores após $11 \mathrm{~h} 30$ da alimentação (1788,2 vs 976,7 e 941,8 mg de BLA/kg de conteúdo ruminal, para 1 h e $2 \mathrm{~h} 30$ após a alimentação, respectivamente), não encontrando diferenças na $\mathrm{MO}$ e no nitrogênio na composição de BLA nos diferentes horários.

Na Tabela 4 são demonstrados as ingestões de MS, MO, CT, EB e N; a matéria orgânica (MOADR), os carboidratos (CHOADR) e a energia aparentemente digeridos no rúmen (EADR); os fluxos de MO, CT, EB, N, microrganismos ruminais, $\mathrm{MO}$ microbiana e $\mathrm{N}$ microbiano; e as eficiências de síntese de proteína microbiana. Não houve diferença significativa entre as dietas avaliadas para os fluxos de nutrientes para o duodeno. O fluxo de nitrogênio para o duodeno foi menor que a quantidade ingerida, refletindo em nitrogênio disponível no retículo-rúmen e no abomaso semelhante entre as dietas (32,8, 34,7 e 30,9 g/dia para as dietas MI, CS e FGM, respectivamente). Esses resultados corroboram os relatados por Galati et al. (2002b), que, avaliando as mesmas dietas utilizadas neste experimento, não observaram diferenças nas concentrações de 
nitrogênio amoniacal ruminal.

Observou-se tendência de menor fluxo de compostos microbianos (MS, MO e N) na dieta MI, ocasionando inferioridade de 18,6 e 17,3\% em relação às dietas CS e FGM, respectivamente, para a eficiência de síntese microbiana (g N mic/kg de MOADR) (Tabela 4).

Grisgby et al. (1993), ao avaliarem a substituição do milho pela casca de soja no concentrado em dietas com 56,8\% de feno de coastcross (Cynodon dactylon, L. Pers.) para novilhos de corte, verificaram maior fluxo de nitrogênio microbiano para a dieta com $66 \%$ casca de soja e $33 \%$ de milho. Encontraram, no entanto, maior eficiência microbiana na dieta com 100\% de milho (30,2 g de N mic/ kg MOADR), e atribuíram os resultados ao menor valor da MOADR obtida neste tratamento.

Cecava et al. (1991) observaram que a adição de amido de milho em dietas aumentou a eficiência microbiana, sem alterar o fluxo de nitrogênio microbiano para o duodeno, mas diminuiu a MOADR. O mesmo fato não foi observado neste experimento, pois as porcentagens de amido das dietas MI e FGM foram semelhantes (26,6 e 24,9\%, respectivamente) e a MOADR foi 316,6 g/dia menor para a dieta MI.
O valor médio encontrado para a eficiência microbiana (22,16 g N mic/kg MOADR) foi inferior ao recomendado pelo ARC (1994), de 30 g N mic/kg MOADR. Ítavo et al. (2002) não observaram efeito significativo do nível de concentrado sobre a produção e eficiência microbiana, obtendo média de 46,11 g N mic/kg CHOADR, que é muito superior ao valor encontrado neste experimento (29,6 g N mic/kg CHOADR). No entanto, Valadares Filho (1995), em revisão, verificou variação de 25,7 a 36,5 g N mic/kg de CHOADR na eficiência microbiana, semelhante aos resultados dessa pesquisa.

A eficiência microbiana expressa na forma adotada pelo NRC (1996), ou seja, g de PB microbiana/100 g de NDT, foi 7,18; 9,89 e 9,75 g de PB mic/100 g de NDT, nas dietas MI, CS e FGM, respectivamente, portanto inferiores à de $13 \mathrm{~g}$ de PB mic/100 g de NDT proposta pelo NRC (1996). Entretanto, esses valores são próximos à média registrada por Ladeira et al. (1999), que, avaliando cinco níveis de concentrado em dietas com feno dos capins braquiária (Brachiaria decumbens, Stapf) e coastcross (Cynodon dactylon, L. Pers.), obtiveram média de 9,42 g de PB mic/100 g de NDT.

A contribuição do nitrogênio microbiano no fluxo total de nitrogênio para o duodeno foi de 53,6\% para a dieta MI,

Tabela 4 - Ingestões de MS, MO, CHO, EB e N; matéria orgânica (MOADR), carboidratos (CHOADR) e energia aparentemente digeridos no rúmen (EADR); fluxos de $\mathrm{MO}, \mathrm{CHO}, \mathrm{EB}, \mathrm{N}$ total, microrganismos ruminais, MO microbiana, $\mathrm{N}$ microbiano; e eficiência de síntese microbiana, de acordo com as dietas experimentais

Table 4 - $\quad D M, O M, C O H, G E$, and N intakes; OM apparently digested in the rumen (OMAD), CHO apparently digested in the rumen (CHOAD), CE apparently digested in the rumen (CEAD); OM, COH, CE, total N, ruminal microbial, microbial OM, microbial $N$ flows and efficiency of microbial synthesis, of each experimental diets

\begin{tabular}{|c|c|c|c|c|}
\hline \multirow[t]{3}{*}{$\begin{array}{l}\text { Ingrediente (\%) } \\
\text { Ingredient (\%) }\end{array}$} & \multicolumn{3}{|c|}{$\begin{array}{c}\text { Dieta } \\
\text { Diet }\end{array}$} & \multirow[t]{3}{*}{ CV (\%) } \\
\hline & MI & CS & FGM & \\
\hline & GC & $S B H$ & $C G M$ & \\
\hline MS ingerida (kg/dia) (DM intake, kg/day) & 9,13 & 9,26 & 9,03 & 7,17 \\
\hline MO ingerida (kg/dia) (OM intake, kg/day) & 8,78 & 8,87 & 8,64 & 7,15 \\
\hline CHO ingerido (kg/dia) (COH intake, $\mathrm{kg} /$ day) & 7,53 & 7,62 & 7,48 & 7,19 \\
\hline EB ingerida (MJ/dia) (GE intake, $M J /$ day) & 167,17 & 172,90 & 160,71 & 6,80 \\
\hline $\mathrm{N}$ ingerido (g/dia) ( $N$ intake, g/day) & 155,79 & 161,56 & 150,52 & 7,42 \\
\hline MOADR (g/dia) (OMAD, g/day) & 3564,6 & 3788,4 & 3881,2 & 13,20 \\
\hline CHOADR (g/dia) (COHAD, g/day) & 2681,4 & 2865,8 & 3011,1 & 16,02 \\
\hline EADR (MJ/dia) (CEAD, MJ/day) & 59,00 & 68,37 & 63,12 & 15,36 \\
\hline \multicolumn{5}{|l|}{ Fluxo para o duodeno (Duodenum flow) } \\
\hline MO (g/dia) (OM, g/day) & 5950,2 & 5131,9 & 5266,1 & 15,11 \\
\hline $\mathrm{CHO}$ (g/dia) $(\mathrm{COH}, \mathrm{g} /$ day $)$ & 5265,4 & 4801,1 & 4957,9 & 15,29 \\
\hline $\mathrm{EB}(\mathrm{MJ} / \mathrm{dia})(C E, M J / d a y)$ & 108,18 & 104,53 & 97,58 & 11,40 \\
\hline $\mathrm{N}$ total (g/dia) (Total $N, \mathrm{~g} /$ day) & 122,98 & 126,85 & 119,56 & 12,80 \\
\hline Microrganismos ruminais (g/dia) (Ruminal microorganisms, g/day) & 1307,4 & 1812,0 & 1711,8 & 29,71 \\
\hline MO microbiana (g/dia) (Microbial OM, g/day) & 734,2 & 1033,0 & 1002,0 & 22,53 \\
\hline N microbiano (g/dia) (Microbial N, g/day) & 65,96 & 88,85 & 85,72 & 14,75 \\
\hline \multicolumn{5}{|l|}{ Eficiência de síntese microbiana (Microbial synthesis efficiency) } \\
\hline N mic/MOADR (g/kg) (Microbial N/OMAD, g/kg) & 19,34 & 23,76 & 23,39 & 32,26 \\
\hline $\mathrm{N}$ mic/CHOADR (g/kg) (Microbial N/COHAD, g/kg) & 26,61 & 31,45 & 30,70 & 33,65 \\
\hline $\mathrm{N}$ mic/EADR (g/MJ) (Microbial N/CEAD, g/kg) & 1,22 & 1,34 & 1,51 & 19,33 \\
\hline
\end{tabular}

Médias nas linhas não diferem $(P<0,05)$ pelo teste Tukey.

Means within a row, do not differ $(P>0.05)$ by Tukey test.

$\mathrm{MI}=$ dieta formulada com milho; CS = substituição parcial do milho pela casca de soja; FGM = substituição parcial do milho pelo farelo de gérmen de milho $\mathrm{CV}=$ coeficiente de variação.

$G C=$ diet formulated with corn; $S B H=$ corn partially replaced with soybean hulls; $C G M=$ corn partially replaced with corn germ meal. $C V=$ coefficient of variation 
70,0\% para a dieta CS e 71,7\% para a dieta FGM. O nitrogênio que chega ao duodeno é proveniente dos microrganismos ruminais, da proteína não-degradada no rúmen e da proteína endógena. O tipo de energia do alimento regula a conversão de nitrogênio amoniacal em proteína microbiana. De acordo com Galati et al. (2002b), as concentrações ruminais de nitrogênio amoniacal, obtidas nas mesmas dietas deste experimento, não variaram, com médias de 25,3; 25,8 e 27,3 mg/100 mL de líquido ruminal para as dietas MI, CS e FGM, respectivamente. Portanto, pode-se inferir que o aproveitamento de nitrogênio amoniacal pelos microrganismos ruminais foi menos eficiente na dieta MI.

Outro fato que pode justificar a menor contribuição de produção microbiana na dieta MI seriam os valores de digestibilidade ruminal da matéria seca, da FDN e do amido, que, apesar de não apresentarem diferença significativa, foram 8,$7 ; 14,6$ e 12,2\%, inferiores à média das demais dietas, respectivamente (Mendes et al., 2005). Esses menores valores de digestibilidade indicam que a fermentação ruminal e o crescimento microbiano foram menos adequados nessa dieta.

Na Tabela 5 encontram-se as médias de volume de líquido ruminal, taxa de diluição, tempo de reciclagem e fluxo do líquido ruminal, estimadas pela concentração do Co-EDTA, de acordo com as dietas avaliadas. Não houve diferença significativa entre as dietas para as variáveis avaliadas. Segundo Owens \& Goetsch (1988), o volume ruminal total em bovinos corresponde de 15 a $21 \%$ do peso vivo. O volume de líquido ruminal neste experimento foi de 8,$45 ; 7,71$ e 7,82\% do peso corporal, para as dietas MI, CS e FGM, respectivamente. Provavelmente, esses valores foram subestimados pela dificuldade de homogeneização instantânea do indicador no rúmen. Vários autores relata- ram problemas na estimativa do volume de líquido ruminal. Silveira (2001) relatou problemas com a utilização do Co-EDTA para a estimativa do volume ruminal, com média de $26 \%$ do peso corporal.

Galloway et al. (1993) avaliaram a suplementação com milho, casca de soja ou milho e casca de soja em novilhos alimentados com feno de capim coastcross (Cynodon dactylon, L. Pers.) e capim dos pomares (Dactilys glomerata) e observaram maiores fluxos com as combinações feno de capim coastcross + casca de soja $(6,67 \mathrm{~L} / \mathrm{h})$ e capim dos pomares + milho e casca de soja $(6,43 \mathrm{~L} / \mathrm{h})$. No entanto, Berchielli et al. (1996) registraram fluxo de 3,09 L/h em novilhos, que foi inferior aos valores relatados neste experimento.

Owens \& Goetsch (1988) relataram relação positiva entre a eficiência de síntese microbiana e a taxa de diluição no rúmen. O aumento da taxa de diluição favorece o desenvolvimento de microrganismos que se dividem mais rapidamente e possuem maior eficiência de utilização de ATP. Neste experimento, não houve diferença significativa entre as taxas de diluição, mas as taxas de diluição da dieta MI foram 5,4 e 11,8\% menores que os valores obtidos para as dietas CS e FGM, respectivamente (Tabela 5), enquanto a eficiência de síntese microbiana (g $\mathrm{N}$ mic/MJ EADR) foi 8,9 e 19,2\% menor que os valores obtidos nas dietas CS e FGM, respectivamente (Tabela 4).

Segundo Martin \& Hibberd (1990), a maior quantidade de casca de soja no suplemento ( 0 a $3 \mathrm{~kg}$ de casca de soja) em dietas para novilhos alimentados com feno de baixa qualidade aumentou $(\mathrm{P}<0,11)$ a taxa de diluição $(8,05$ a 9,50\%/h). Todavia, Grigsby et al. (1993) não observaram efeito da substituição do milho pela casca de soja e obtiveram valores médios de 9,5\%/h.

Tabela 5 - Volume, taxa de diluição, taxa de reciclagem e fluxo do líquido ruminal estimados por meio do Co-EDTA nos novilhos alimentados com as dietas experimentais

Table 5 - $\quad$ Ruminal fluid volume, dilution rate, recycle rate and fluid flow estimated with Co-EDTA in steers fed experimental diets

\begin{tabular}{|c|c|c|c|c|}
\hline \multirow[t]{3}{*}{$\begin{array}{l}\text { Ingrediente (\%) } \\
\text { Ingredient (\%) }\end{array}$} & \multicolumn{3}{|c|}{$\begin{array}{l}\text { Dieta } \\
\text { Diet }\end{array}$} & \multirow[t]{3}{*}{ CV (\%) } \\
\hline & MI & CS & FGM & \\
\hline & GC & $S B H$ & CGM & \\
\hline Volume de líquido ruminal (L) & 40,25 & 38,06 & 34,86 & 24,39 \\
\hline Ruminal fluid volume $(L)$ & & & & \\
\hline $\begin{array}{l}\text { Taxa de diluição (\%/h) } \\
\text { Dilution rate }(\% / h)\end{array}$ & 12,59 & 13,31 & 14,28 & 16,03 \\
\hline $\begin{array}{l}\text { Tempo de reciclagem (horas) } \\
\text { Recycle rate (hours) }\end{array}$ & 8,59 & 7,75 & 7,11 & 15,13 \\
\hline $\begin{array}{l}\text { Fluxo }(\mathrm{L} / \mathrm{h}) \\
\text { Flow }(L / h)\end{array}$ & 4,75 & 4,97 & 5,02 & 22,07 \\
\hline
\end{tabular}

Médias nas linhas não diferem $(P<0,05)$ pelo teste Tukey.

Means within a row, do not differ $(P>0.05)$ by Tukey test.

$\mathrm{MI}=$ dieta formulada com milho; CS = substituição parcial do milho pela casca de soja; FGM = substituição parcial do milho pelo farelo de gérmen de milho. $\mathrm{CV}=$ coeficiente de variação.

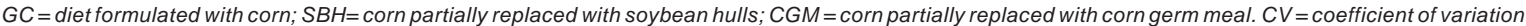


A concentração de cromo no conteúdo ruminal neste trabalho atingiu maior valor no primeiro horário de coleta e 3 horas após sua introdução no rúmen, para o farelo de girassol e os ingredientes energéticos, e 6 horas para a silagem mordentada. O intervalo de 24 horas para administração dos ingredientes mordentados foi suficiente para que não houvesse resíduo de cromo na coleta posterior. As concentrações de cromo nas amostras coletadas imediatamente antes da introdução do indicador no rúmen foram irrisórias, provavelmente em razão do tempo de retenção das fontes energéticas e do farelo de girassol no retículorúmen, que foram inferiores a 24 horas.

Na Figura 1 consta o tempo de retenção de cada ingrediente no retículo-rúmen (TRRR), de acordo com as dietas utilizadas. Constatou-se que a silagem de milho apresentou maior TRRR, mas foi sempre a última a ser administrada em cada período, não interferindo na amostragem dos demais ingredientes.

Houve diferença significativa $(\mathrm{P}<0,05)$ para silagem de milho mordentada, de modo que a dieta MI apresentou menor velocidade de passagem (Figura 2) e superioridade no TRRR (33,6 e 25,7\%) em relação às dietas CS e FGM, respectivamente (Figura 1 ).

Em trabalho realizado simultaneamente a este, Mendes et al. (2005) utilizaram as mesmas dietas e constataram que os valores de digestibilidade ruminal da FDA foram significativamente menores na dieta MI (35,26\%) e maiores na CS (47,18\%), enquanto os da dieta FGM não diferiram das demais (39,89\%). Considerando que a ingestão de matéria seca pelos animais foi semelhante entre as dietas, os maiores valores de digestibilidade ruminal da fibra nas dietas CS e FGM possivelmente promoveram os maiores valores de taxa de passagem e, conseqüentemente, os menores de TRRR (Figura 1).

Os resultados obtidos na silagem de milho e no farelo de girassol mordentados e as respectivas equações, de acordo com as dietas MI, CS e FGM, encontram-se nas Figuras 2 e 3.

Henriques et al. (2001), ao avaliarem a taxa de passagem ruminal da silagem de milho em animais mestiços Holandês x Zebu alimentados somente com silagem, obtiveram valores de 2,75\%/h e TRRR de 36,6 horas, semelhantes aos encontrados na dieta MI.

Não houve diferença significativa nos valores de taxa de passagem e TRRR do farelo de girassol entre as diferentes dietas (Figuras 3 e 1). Todavia, a estimativa de sua taxa de passagem na dieta MI foi 17,73\% inferior à média das demais dietas, comportamento semelhante ao ocorrido com a silagem de milho mordentada. Ressalta-se que a fração protéica do farelo de girassol é altamente solúvel, em torno de 56,3\% (Galati et al., 2002c) e provavelmente não apresenta trânsito semelhante ao do farelo de girassol mordentado, uma vez que o cromo se fixa na parede celular e, durante o preparo da fibra mordentada, possivelmente a fração solúvel do ingrediente é eliminada.

Bürger et al. (2000) não observaram influência do nível de concentrado sobre o TRRR do feno de capim coastcross (média de 25,6 horas), mas, no farelo de soja mordentado, constataram decréscimo linear de acordo com os níveis crescentes de concentrado, com valor de 13,4 horas para a dieta com $45 \%$ de concentrado. $O$ farelo de girassol utilizado neste experimento apresentou TRRR maior (média de 18,1 horas; Figura 1) que a casca de soja, provavelmente em razão de sua composição fibrosa (55,5\% FDN) em relação ao farelo de soja (14,9\% FDN, segundo o NRC, 1996) e dos elevados valores da fração indigestível (fração c) (30,6\% MS; 62,9\% FDN; 61,4\% FDA, Galati et al., 2002c).

A alta taxa de passagem pode aumentar a eficiência de fermentação ao diminuir os gastos com manutenção das bactérias e a reciclagem microbiana no rúmen, disponibilizando maior quantidade de nitrogênio e energia para o crescimento microbiano (Waldo, 1986). Os maiores valores de taxa de passagem das dietas CS e FGM podem ter favorecido a reciclagem das bactérias celulolíticas no rúmen, aumentando a eficiência microbiana, uma vez que apresentaram valores numericamente maiores que a dieta MI.

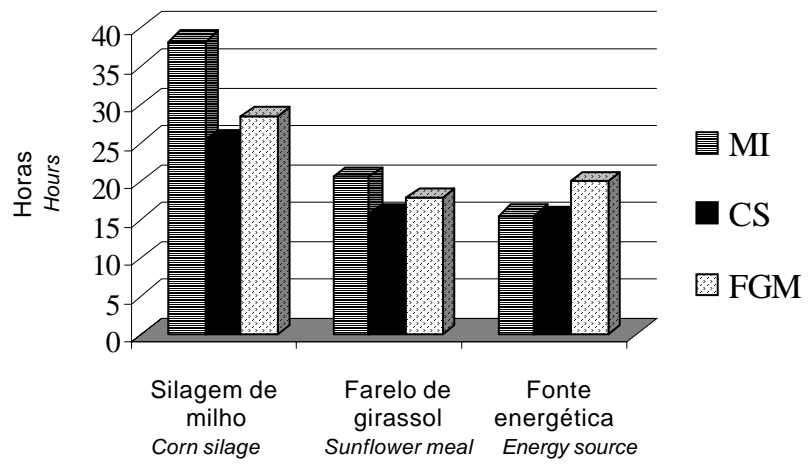

Figura 1 - Tempo de retenção no retículo rúmen (h) dos ingredientes $\mathrm{Cr}$-mordentados em cada dieta experimental. $\mathrm{MI}=$ dieta formulada com milho; $\mathrm{CS}$ = substituição parcial do milho pela casca de soja; FGM = substituição parcial do milho pelo farelo de gérmen de milho.

Figure 1 - Reticulum rumen retention time (h) of Cr-mordanted ingredients on each experimental diet.

$G C=$ diet formulated with corn; $S B H=$ corn partially replaced with soybean hulls; CGM = corn partially replaced with corn germ meal. 


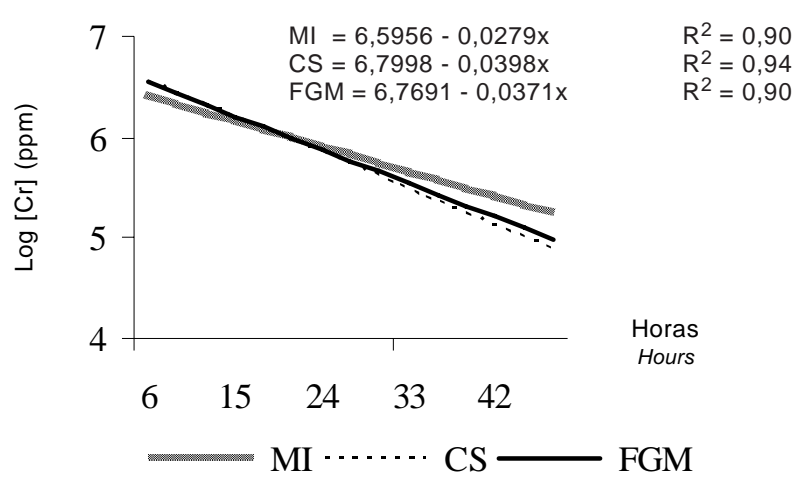

Figura 2 - Taxas de passagem da silagem de milho mordentada em cada dieta experimental.

$\mathrm{MI}=$ dieta formulada com milho; $\mathrm{CS}$ = substituição parcial do milho pela casca de soja; FGM = substituição parcial do milho pelo farelo de gérmen de milho.

Figure 2 - Passage rate of mordanted corn silage on each experimental diet.

$G C=$ diet formulated with corn; $S B H=$ corn partially replaced with soybean hulls; CGM = corn partially replaced with corn germ meal.

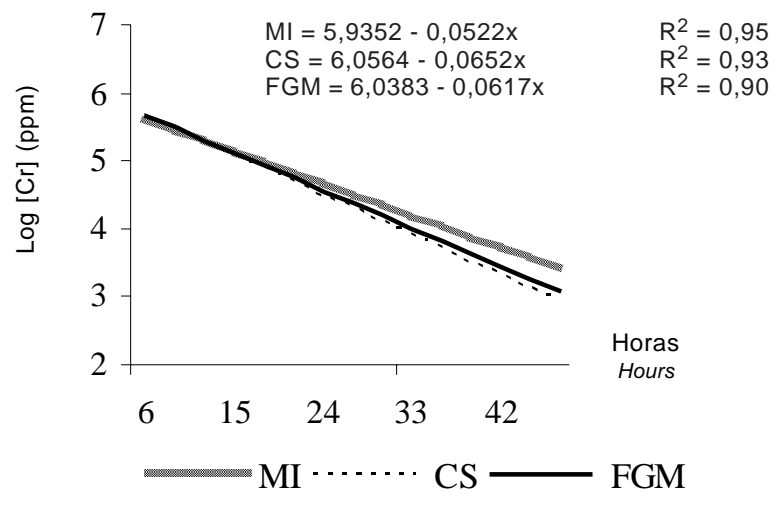

Figura 3 - Taxas de passagem do farelo de girassol mordentado em cada dieta experimental.

$\mathrm{MI}=$ dieta formulada com milho; CS = substituição parcial do milho pela casca de soja; FGM = substituição parcial do milho pelo farelo de gérmen de milho.

Figure 3 - Passage rate of mordanted sunflower meal on each experimental diet.

$G C=$ diet formulated with corn; $S B H=$ corn partially replaced with soybean hulls; $C G M=$ corn partially replaced with corn germ meal.

Constam na Figura 4 as taxas de passagem do milho, da casca de soja e do farelo de gérmen de milho mordentados e as respectivas equações para cada dieta em que o ingrediente foi utilizado. Acredita-se que o alto coeficiente de variação (54\%) para a taxa de passagem das fontes energéticas milho, casca de soja e farelo de gérmen de milho seja conseqüência da técnica de marcação da fibra com dicromato de sódio, possivelmente pelo baixo teor de

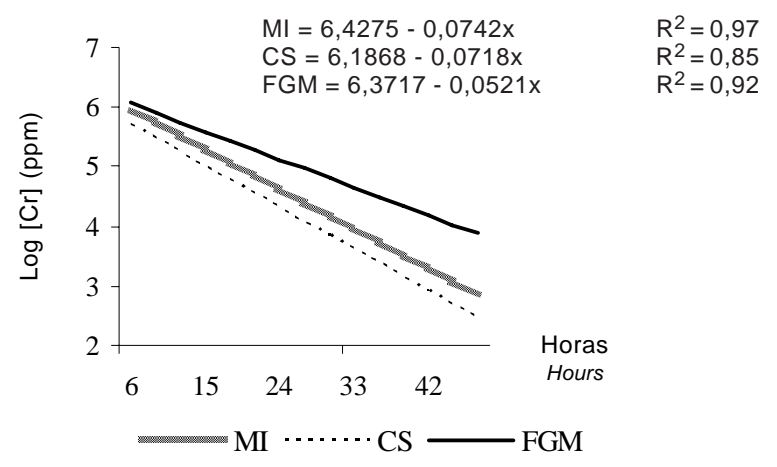

Figura 4 - Taxas de passagem do milho, da casca de soja e do farelo de gérmen de milho mordentados. $\mathrm{Ml}=$ dieta formulada com milho; $\mathrm{CS}=$ substituição parcial do milho pela casca de soja; FGM = substituição parcial do milho pelo farelo de gérmen de milho.

Figure 4 - Passage rate of mordanted corn, soybean hulls and corn meal. $G C=$ diet formulated with corn; $S B H=$ corn partially replaced with soybean hulls; CGM = corn partially replaced with corn germ meal.

carboidrato estrutural ou pelo seu arranjamento nesses ingredientes.

Galloway et al. (1993), avaliando a suplementação com milho e casca de soja em novilhos alimentados com feno de capim coastcross (Cynodon dactylon, L. Pers.), observaram maiores valores de taxa de passagem para dieta com casca de soja (4,50 vs 3,64\%/h). Grisgby et al. (1993), no entanto, não encontraram diferença na taxa de passagem de sólidos e líquidos em novilhos alimentados com feno de capim coastcross recebendo suplementação com milho e/ou casca de soja.

A maior porcentagem de FDN da dieta CS (55,5 vs 49,8\% da dieta MI e 51,5\% da dieta FGM) não influenciou sua taxa de passagem, provavelmente em razão da baixa efetividade dessa fibra, o que resulta em menores estímulos nas contrações ruminais.

\section{Conclusões}

A substituição parcial do milho pela casca de soja e pelo farelo de gérmen de milho melhorou a produção e eficiência microbiana, aumentando a contribuição da proteína microbiana que chegou ao duodeno. Não influenciou a taxa de diluição (média de $13,4 \% / \mathrm{h}$ ), mas aumentou a taxa de passagem da silagem de milho mordentada.

A casca de soja e o farelo de gérmen de milho possuem bom potencial quando associados ao farelo de girassol em dietas para novilhos alimentados com silagem de milho. 


\section{Agradecimento}

À Caramuru Alimentos Ltda, pela doação do farelo de girassol, da casca de soja e do farelo de gérmen de milho.

\section{Literatura Citada}

ASSOCIATION OF OFFICIAL ANALYTICAL CHEMISTS - AOAC. Official methods of analysis. 16.ed. Arlington: Patricia Cunniff, 1995. 1025p.

AGRICULTURAL RESEARCH COUNCIL - ARC. The nutrient requirements of ruminant livestock. London: Commonwealth Agricultural Bureau, 1994. 45p.

BERCHIELLI, T.T.; RODRIGUEZ, N.M.; GONÇALVES, L.C. Polietilenoglicol e cobalto-EDTA como marcadores da fase líquida ruminal. Arquivo Brasileiro de Medicina Veterinária e Zootecnia, v.48, n.4, p.463-471, 1996.

BÜRGER, P.J.; PEREIRA, J.C.; VALADARES FILHO, S.C. et al. Taxas de passagem e cinética da degradação ruminal em bezerros holandeses alimentados com dietas contendo diferentes níveis de concentrado. Revista Brasileira de Zootecnia, v.29, n.1, p.225-235, 2000.

CECAVA, M.J.; MERCHEN, N.R.; GAY, L.C. et al. Composition of ruminal bacteria harvested from steers as influenced by dietary energy level, feeding frequency, and isolation techniques. Journal of Dairy Science, v.73, n.9, p.2480-2488, 1990.

CECAVA, M.J.; MERCHEN, N.R.; BERGER, L.L. et al. Effects of dietary energy level and protein source on nutrient digestion and ruminal nitrogen metabolism in steers. Journal of Animal Science, v.69, n.5, p.2230-2243, 1991.

CLARK, J.H.; KLUSMEYER, T.H.E.; CAMERON, M.R. Microbial protein synthesis and flows of nitrogen fractions to the duodenum of dairy cows. Journal of Dairy Science, v.75, n.8, p.2304-2323, 1992.

ERAMUS, L.J.; BOTHA, P.M.; MEISSNER, H.H. Effect of protein source on ruminal fermentation and passage of amino acids to the small intestine of lactating cows. Journal of Dairy Science, v.77, n.12, p.3655-3665, 1994.

EZEQUIEL, J.M.B.; MELÍCIO, S.P.L.; SANCANARI, J.B.D. et al. Quantificação das bactérias sólido aderidas, bactérias e protozoários líquido associados do rúmen de bovinos jovens alimentados com amiréia. Revista Brasileira de Zootecnia, v.31, n.2, p.707-715, 2002.

GALATI, R.L.; EZEQUIEL, J.M.B.; MENDES, A.R. et al. Cinética da digestão ruminal in situ do farelo de girassol utilizado em dietas para bovinos. In: REUNIÃO ANUAL DA SOCIEDADE BRASILEIRA DE ZOOTECNIA, 39., 2002, Recife. Anais... Recife: Technomedia, 2002a. CD-ROM. Nutrição de Ruminantes.

GALATI, R.L.; EZEQUIEL, J.M.B; MENDES, A.R. et al. Influência de diferentes fontes energéticas sobre os valores de $\mathrm{pH}$ e concentrações ruminais de nitrogênio amoniacal no rúmen e no intestino. In: REUNIÃO ANUAL DA SOCIEDADE BRASILEIRA DE ZOOTECNIA, 39., 2002, Recife. Anais... Recife: Technomedia, 2002b. CD-ROM. Nutrição de Ruminantes.

GALATI, R.L.; EZEQUIEL, J.M.B; MENDES, A.R. et al. Cinética da digestão ruminal in situ do farelo de girassol utilizado em dietas para bovinos. In: REUNIÃO ANUAL DA SOCIEDADE BRASILEIRA DE ZOOTECNIA, 39., 2002, Recife. Anais... Recife:Thecnomedia, 2002c. CD-ROM. Nutrição de Ruminantes.

GALLOWAY, D.L.; GOETSH, A.L.; FORSTER, L.A. et al. Feed intake and digestibility by cattle consuming bermudagrass or orchardgrass hay supplemented with soybean hulls and (or) corn. Journal of Animal Science, v.71, n.11, p.3087-3095, 1993.
GRIGSBY, K.N.; KERLEY, M.S.; PATERSON, J.A. et al. Combinations of starch and digestible fiber in supplements for steers consuming a low- quality bromegrass hay diet. Journal of Animal Science, v.71, n.4, p.1057-1064, 1993.

HENDRIX, D.L. Rapid extraction and analysis of nonstructural carbohydrates in plant tissues. Crop Science, v.33, n.6, p.1306$1311,1993$.

HENRIQUES, L.T.; COELHO DA SILVA, J.F.; VÁSQUEZ, H.M. et al. Efeito do acipin sobre a degradabilidade e taxa de passagem de silagens de capim elefante e de milho em bovinos mestiços Holandês x Zebu. In: REUNIÃO ANUAL DA SOCIEDADE BRASILEIRA DE ZOOTECNIA, 38., 2001, Piracicaba. Anais... Piracicaba: Sonopress, 2001. p.1321-1322. CD-ROM. Áreas técnicas, Nutrição de Ruminantes.

ÍTAVO, L.C.V.; VALADARES FILHO, S.C.; SILVA, F.F. et al. Produção microbiana e parâmetros ruminais de novilhos alimentados com dietas contendo vários níveis de concentrado. Revista Brasileira de Zootecnia, v.31, n.3, p.1553-1561, 2002 (suplemento).

KOVÁCS, P.L.; SÜDEKUN, K.H.; STANGASSINGER, M. Effects of intake of mixed diets and time post feeding on amount and fiber composition of ruminal and fecal particles and on digesta passage from the reticulo-rumen of steers. Animal Feed Science and Technology, v.71, n.3-4, p.325-340, 1998.

LADEIRA, M.M.; VALADARES FILHO, S.C.; COELHO DA SILVA, J.F. et al. Eficiência microbiana, concentração de amônia e $\mathrm{pH}$ ruminal e perdas nitrogenadas endógenas, em novilhos Nelore. Revista Brasileira de Zootecnia, v.28, n.2, p.404-411, 1999.

MANSFIELD, H.R.; STERN, M.D. Effects off soybean hulls and lignosulfonate-treated soybean meal on ruminal fermentation in lactating dairy cows. Journal of Dairy Science, v.77, n.4, p.1070-1083, 1994.

MARTIN, S.K.; HIBBERD, C.A. Intake and digestibility of lowquality native grass hay by beef cows supplemented with graded levels of soybean hulls. Journal of Animal Science, v.68, n.12, p.4319-4325, 1990.

MENDES, A.R.; EZEQUIEL, J.M.B.; GALATI, R.L. et al. Consumo e digestibilidade total e parcial de dietas utilizando farelo de girassol e três fontes de energia em novilhos confinados. Revista Brasileira de Zootecnia, v.34, n.2, p.679-691, 2005.

MILLER, G.L. Use of dinitrosalicylic acid reagent for determination of reducing sugar. Analytical Chemistry, v.31, n.3, p.426-428, 1959.

NASCIMENTO FILHO, V.F.; ABDALLA, A.L.; KORNDORFER, A.A. et al. Sensibilidades analíticas de diferentes modos de excitação em fluorescência de raios $\mathrm{X}$ para medida de traçadores em fezes de animais. In: ENCONTRO CIENTÍFICO DE PÓS GRADUANDOS DO CENA/USP, 3., 1997, Piracicaba. Anais... Piracicaba: CENA/USP, 1997. p.69.

NATIONAL RESEARCH COUNCIL - NRC. Nutrient requirements of beef cattle. 7.ed. Washington, D.C.: National Academic Press, 1996. 242p.

ORSKOV, E.R.; McDONALD, I. The estimation of protein degradability in the rumen from incubation measurements wighted according to rate of passage. Journal of Agricultural Science, v.92, n.2, p.499-503, 1979.

OWENS, F.N.; GOETSCH, A.L. Fermentación ruminal. In: CHURCH, D.C. (Ed.) El rumiante: fisiologia digestiva y nutricion. Zaragoza: Acribia, 1988. p.159-190.

STATISTICAL ANALYSIS SYSTEMS - SAS. Language guide. 3.ed. Cary: 1995. v.6, 530p.

SILVA, D.J.; QUEIROZ, A.C. Análise de alimentos (métodos químicos e biológicos). 3.ed. Viçosa, MG: Universidade Federal de Viçosa, 2002. 235p.

SILVEIRA, R.N. Avaliação nutricional de silagens de resíduos de mandioca e de cana-de-açúcar, com polpa cítrica, para bovinos. Jaboticabal: Universidade Estadual Paulista, 2001. 48p. Dissertação (Mestrado em Produção Animal) - Universidade Estadual Paulista, 2001. 
SNIFFEN, C.J.; O’CONNOR, J.D.; Van SOEST, P.J. et al. A net carbohydrate and protein system for evaluating cattle diets: II. Carbohydrate and protein availability. Journal of Animal Science, v.70, n.11, p.3562-3577, 1992

UDÉN, P.; COLUCCI, P.E.; Van SOEST, P.J. Investigation of chromium, cerium and cobalt as markers in digesta. Rate of passage studies. Journal of Science Food and Agriculture, v.31, n.2, p.625-638, 1980.

VALADARES FILHO, S.C. Eficiência de síntese de proteína microbiana, degradação ruminal e digestibilidade intestinal da proteína bruta, em bovinos. In: SIMPÓSIO INTERNACIONAL SOBRE EXIGÊNCIAS NUTRICIONAIS DE RUMINANTES. 1., 1995, Viçosa, MG. Anais... Viçosa, MG: Universidade Federal de Viçosa, 1995. p.354-388.

Van ESPEN, P.; JANSSENS, P.; SWENTER, S. 1 AXIL -X-ray Analysis Software: users manual. Bebelux: Packlard, s.d. 72p.
Van SOEST, P.J. Nutritional ecology of the ruminant. 2.ed. Ithaca: Cornell, 1994. 476p.

WALDO, D.R. Effect of forage quality on intake and forageconcentrate interactions. Journal of Dairy Science, v.69, n.4, p.617-631, 1986.

ZINN, R.A.; OWENS, F.N. A rapid procedure for purine measurement and its use for estimating net ruminal protein synthesis. Canadian Journal of Animal Science, v.66, n.1, p.157-166, 1986. 